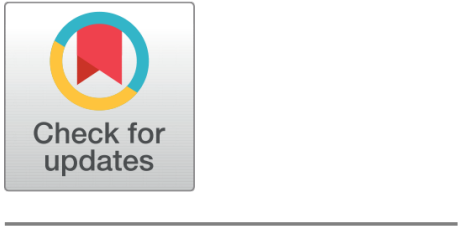

OPEN ACCESS

Received: 15.10 .2020

Accepted: 23.12 .2020

Published: 08.04 .2021

Citation: Khan MS, Kakar FK, Saeed M, Khan A, Ali B, Ashraf M, Khan S, Tareen AW (2021) Economic analysis of DC power sources used in impressed current cathodic protection of underground pipelines. Indian Journal of Science and Technology 14(10): 897-904. htt ps://doi.org/

10.17485/IJST/v14i10.1870

* Corresponding author.

kakar1971@gmail.com

Funding: None

Competing Interests: None

Copyright: (c) 2021 Khan et al. This is an open access article distributed under the terms of the Creative Commons Attribution License, which permits unrestricted use, distribution, and reproduction in any medium, provided the original author and source are credited.

Published By Indian Society for Education and Environment (iSee)

ISSN

Print: 0974-6846

Electronic: 0974-5645

\section{Economic analysis of DC power sources used in impressed current cathodic protection of underground pipelines}

\author{
Muhammad Saddam Khan ${ }^{1}$, Faizullah Khan Kakar ${ }^{1 *}$, Muhammad Saeed ${ }^{2}$, \\ Akbar Khan ${ }^{1}$, Babar Ali ${ }^{1}$, Muhammad Ashraf1, Surat Khan ${ }^{1}$, \\ Abdul Wahid Tareen ${ }^{1}$ \\ 1 Faculty of Information and Communication Technology, Balochistan University of \\ Information Technology Engineering and Management Sciences (BUITEMS), Quetta, Pakistan \\ 2 FAST National University of Computer and Emerging Sciences Islamabad, Pakistan
}

\section{Abstract}

Objective: The objective of this study is to calculate and analyze the economic parameters of three main DC power sources i.e. Thermoelectric Generator, Transformer Rectifier, and solar photovoltaic (PV) Solar System, which are widely used in impressed current cathodic protection (ICCP) of underground pipelines. Methodology/Analysis : Initial or capital cost, operation and maintenance costs of the afore-mentioned DC sources are computed, for a practical ICCP system of high transmission underground pipeline over a period. Present worth analysis technique of economic analysis with inflation adjustment using a spreadsheet is adopted to compute these values. The analysis period of 20 years is used for present worth calculations of these DC sources. Findings: The cost efficiency of DC power sources for an ICCP system have been discussed in very few research papers. The calculations are made for either only one DC source at a time or the comparison is based on calculation without inflation adjustment. This study, in line with the currently adopted methodologies, provides a far easier and more comprehensive comparison and analysis of the most economical DC source for the ICCP system of underground metallic pipelines. Novelty/ Improvement: DC power sources play a pivotal role in an ICCP system that helps to mitigate the rate of corrosion in underground pipelines. This study contributes towards choosing the costeffective DC Power source for an ICCP system of underground pipelines. The results are drawn using practical data. This subsequently helps in mitigating the rate of corrosion in these pipelines.

Keywords: Economic analysis; corrosion; DC power source; impressed current cathodic protection; underground pipelines

\section{Introduction}

Corrosion is an inevitable phenomenon that impacts all the metals that are exposed to the environment. To save a metal surface from corrosion attack, either application of 
corrosion resistive materials, such as stainless steel or plastic is used, or by electrically isolating a metal surface from the environment in which it is kept i.e. protecting it with cathodic protection as the second line of defense. ${ }^{(1)}$

The first line of defense for underground metallic pipelines is the use of protective coatings that isolate a metal surface from the electrolyte. But these coatings get or damages due to third party actions that reduce the effectiveness of protective coatings. Therefore, to achieve $100 \%$ protection from corrosion, a cathodic protection technique in conjunction with the protective coatings is used. ${ }^{(1)}$

Cathodic protection can either be provided by sacrificial anode cathodic protection method (SACP) or by impressed current cathodic protection method (ICCP). ${ }^{(2)}$

The application of these two methods is driven by the resistivity of the electrolyte and surface area of the structure to be protected. In a low resistive environment and for a relatively smaller structure or well-coated pipes where the current requirement is limited, SACP system is used. Whereas, in high resistive environments for larger buried structures where a large current is required to cathodically protect the metallic structure, ICCP system is used. ${ }^{(3)}$

The fundamental elements in both methods include anode (metal that has to corrode), cathode (a metal which has to be protected), and electrolyte in which both anode and cathode are to be kept. A DC Power source is additionally used in ICCP system. Schematic diagrams of both the techniques are illustrated in Figures 1 and 2 respectively.

In general, the principle of both cathodic protection techniques is to provide electrons to a protected metal that loses its electrons due to corrosion by providing a stream of electrons and so-termed as cathodic protection.

In an SACP system provision of negatively charged ions (electrons) to the cathode is ensured by making an electrical connection between a more Nobel metal (cathode that has to be protected) and a less Nobel metal (termed as an anode that has to be sacrificed) by keeping both the metals within the same electrolyte (Soil). Electrons start to migrate from metal that is less Nobel towards metal that is more Nobel as per electromotive series.

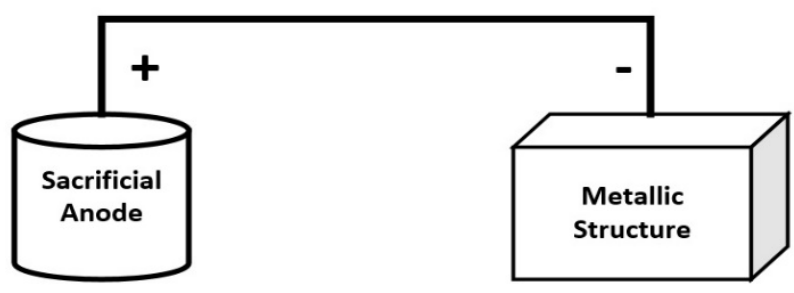

Fig 1. Schematic diagram of Sacrificial Anode Cathodic Protection System

In ICCP system an external DC Power source is used to impress the current (electrons) from a metal that is more Nobel in nature (anode). To provide these impressed electrons to the structure which has to be protected (cathode), the metallic structure is hence cathodically polarized.

An ICCP system is more robust and versatile than SACP especially in an environment where the current requirement is higher or where a large metallic structure is to be cathodically protected. ${ }^{(2)}$

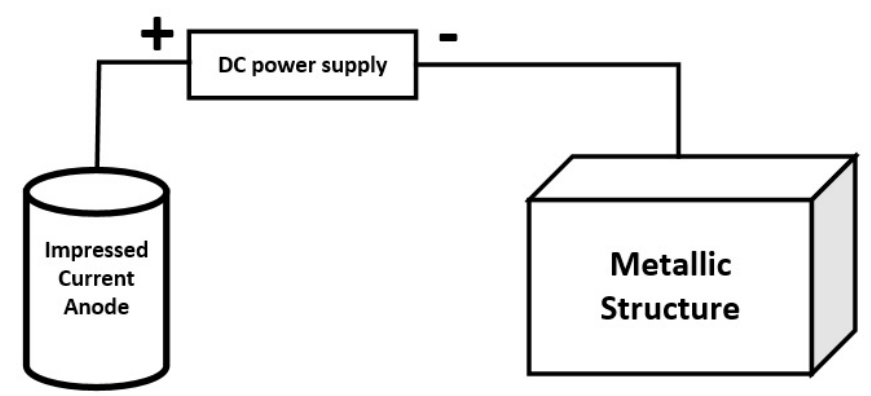

Fig 2. Schematic Diagram of Impressed Current Cathodic Protection

A DC power source plays a vital role in an ICCP system as it affects the overall efficiency of the system and deters the rate of corrosion. 
Therefore, the selection of an efficient and economical DC Power source is an important consideration for impressed current cathodic protection system.

The objective of this paper is to focus on the economic parameters of three major DC Power sources that are mainly used in impressed current cathodic protection of underground pipelines.

\subsection{Literature Survey}

Corrosion in underground pipelines has been a subject of extreme importance. Various researchers have studied corrosion and ICCP system for underground pipelines.

(1) The author Experimented solar cells as a rectifier to provide impressed current cathodic protection to a temporary setup of Mild steel pipes. The research concluded that a sample of buried pipelines without cathodic protection experienced corrosion whereas a set of buried pipelines that were protected by a temporary ICCP system empowered by solar cells got saved from corrosion up to $64.2 \%$ in 40 days of the experiment. The research work was based on the basic principle of cathodic protection.

In our previous paper ${ }^{(2)}$ in-depth analysis of the technical, as well as the cost-efficiency of aforesaid DC sources, was provided. However, a different methodology is employed in the present study for computing cost efficiency of DC sources.

It is evident in the experimental study ${ }^{(3)}$, that the rate of corrosion in iron pipelines can be mitigated using a solar-powered ICCP system. ${ }^{(4)}$ Proposed an automatic regulating system for reducing over protection damages in ICCP system that utilizes a solar system as a rectifier.

In ${ }^{(5)} \mathrm{CP}$ technique for protecting concrete structures from corrosion attack using a transformer rectifier is discussed in general.

The author in ${ }^{(6)}$ has centered upon generating energy from the environment with Triboelectric Nano generator (TENG) for cathodic protection of steel. Cost-effectiveness of the system harvesting energy needs is yet to be carried out.

It is pertinent to note that an efficient constant DC source is important for an effective ICCP System. Hence economic parameters of such a source are the factors that are important to be considered. This study is, therefore, aimed at calculation and analysis of the economic parameters and cost comparison of three main DC power sources used i.e. thermoelectric generator (TEG), transformer rectifier (TR), and a solar PV system. The results are based on real-time implemented data. The adopted methodology and real-time data make this research study a first of its kind. The work will help industrial and commercial sectors in the selection of cost-efficient un-intermittent DC power source for an impressed current cathodic protection system of underground pipelines.

\section{Material and Methods}

To achieve the research objective, a 12-inch diameter underground high transmission natural gas pipeline made up of mild steel material at two different locations, Sibi and Bolan in Balochistan Province of Pakistan differing in resistivity of soil and climate were chosen.

Three DC sources i.e. thermoelectric generator (TEG), transformer rectifier (TR), and a solar PV system of a similar power capacity of $220 \mathrm{~W}$ are implemented one by one and analyzed in a pre-determined impressed current cathodic protection system at both locations. Cost analysis was carried out with the help of present worth analysis with an inflation adjustment of 20 years useful life using Microsoft Excel spreadsheet version 2013.

For economic analysis, cash flow expressed in the future is used to calculate the present worth (PW) value. Estimated annual maintenance and operation costs throughout the useful life of the DC power sources were taken and are mentioned in Figures 5 , 6 and 7.

The following parameters were considered as common for all the three DC power sources:

Useful life of $=20$ Years, USD to PKR exchange rate of Rs.154.76 (as of 24 December 2019).

Inflation adjusted interest rate $\left(i_{f}\right)$ is calculated using formula

$$
\mathrm{i}_{\mathrm{f}}=\mathrm{i}+\mathrm{f}+(\mathrm{i} \times \mathrm{f})
$$

(7) Where,

$\mathrm{i}=$ Real interest rate

$\mathrm{f}=$ Inflation rate

Since the calculation is carried out for 20 years so the inflation-adjusted interest rate $\left(i_{f}\right)$ is calculated by considering the average real interest rate (i) and average inflation rate (f) in Pakistan for the last 20 years i.e. from 2000 to 2019 . Values are given in Figures 3 and 4. 


\subsection{Interest rates in Pakistan from 2000 to 2019}

Figure 3 below is a graphical trend of interest rates issued by State bank of Pakistan for the last 20 years.

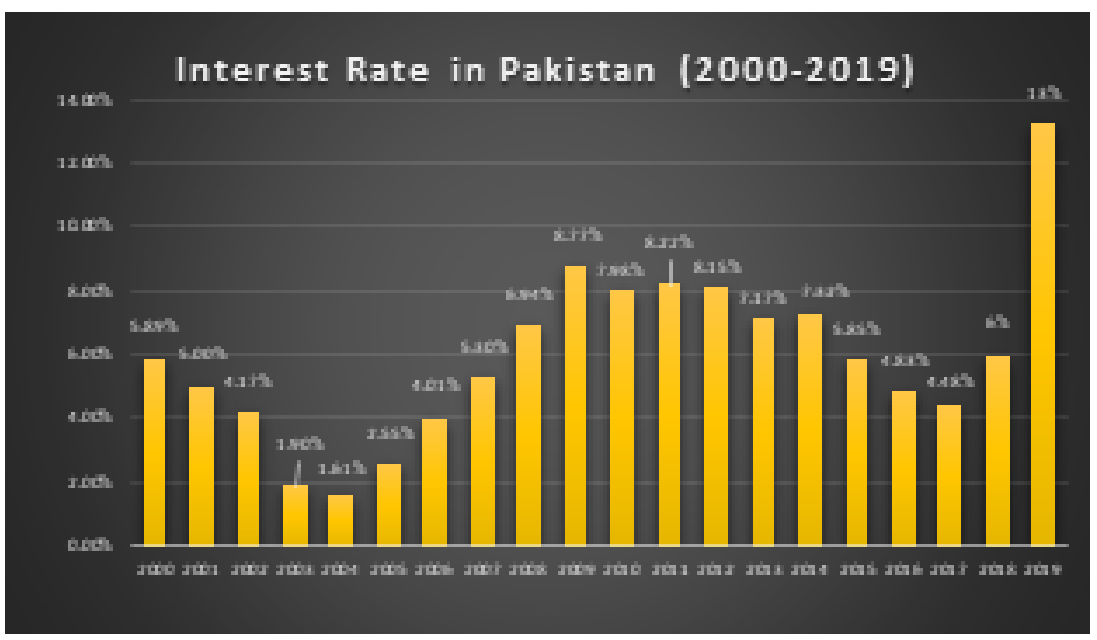

Fig 3. Rate of Interest in Pakistan from 2000-2019

\subsection{Inflation rates in Pakistan from 2000 to 2019}

Figure 4 below depicts the general trend of inflation in Pakistan for the last 20 years.

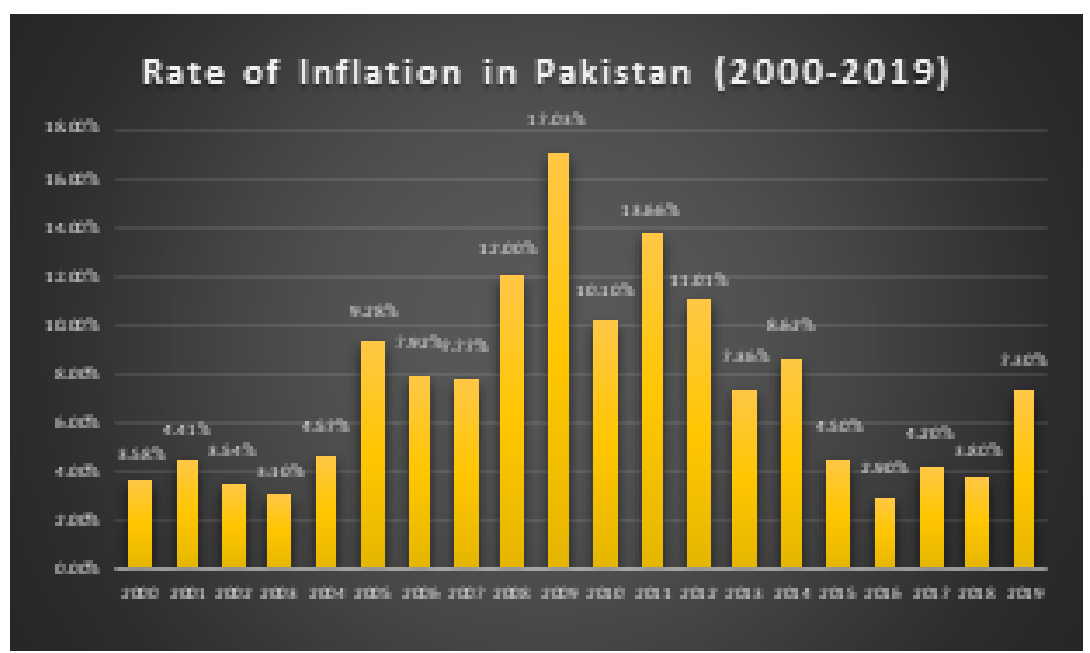

Fig 4. Rate of Inflation in Pakistan from 2000-2019 ${ }^{(8)}$

\subsection{Average inflation rate (f)}

In the presence of inflation in economy the future value can be calculated for the present investment by formula:

$$
\mathrm{F}=\mathrm{P}(1+\mathrm{f})^{\mathrm{n}}
$$

Solving for inflation

$$
f=(\mathrm{F} / \mathrm{P})^{1 / \mathrm{n}}-1
$$


Where,

$\mathrm{f}=$ Inflation rate

$\mathrm{P}=$ present value dollar or Base price

$\mathrm{F}=$ Future value Dollar

$\mathrm{n}=$ Number of years

$\mathrm{F}=$ Base price $\left(1+\mathrm{f}_{1}\right)\left(1+\mathrm{f}_{2}\right) \ldots \ldots \ldots \ldots\left(1+\mathrm{f}_{n}\right)$

Let Base price $=\$ 100$

$$
\begin{gathered}
F=100[(1.0358)(1.0441)(1.0354)(1.0310)(1.0457)(1.0928)(1.0792)(1.0777)(1.1200)(1.1703)(1.1010)(1.1366)(1.02)(1.045)(1.0290)(1.0420)(1.0380)(1.0730)] \\
(1.1101)(1.0736)(1.0862)(1.0658) \\
\mathrm{F}=\$ 406.58
\end{gathered}
$$

Now,

$$
\begin{aligned}
& \mathrm{f}=(\mathrm{F} / \mathrm{P})^{1 / \mathrm{n}}-1 \\
& \mathrm{f}=(406.58 / 100)^{1 / 20}-1 \\
& \mathrm{f}=1.0726-1
\end{aligned}
$$

Average inflation rate of 20 years $=\mathrm{f}=0.0726$

\subsection{Average interest rate (i)}

$$
\mathrm{F}=\mathrm{P}(1+\mathrm{i})^{\mathrm{n}}
$$

Solving for average interest rate

$$
i=(\mathrm{F} / \mathrm{P})^{1 / \mathrm{n}}-1
$$

Where,

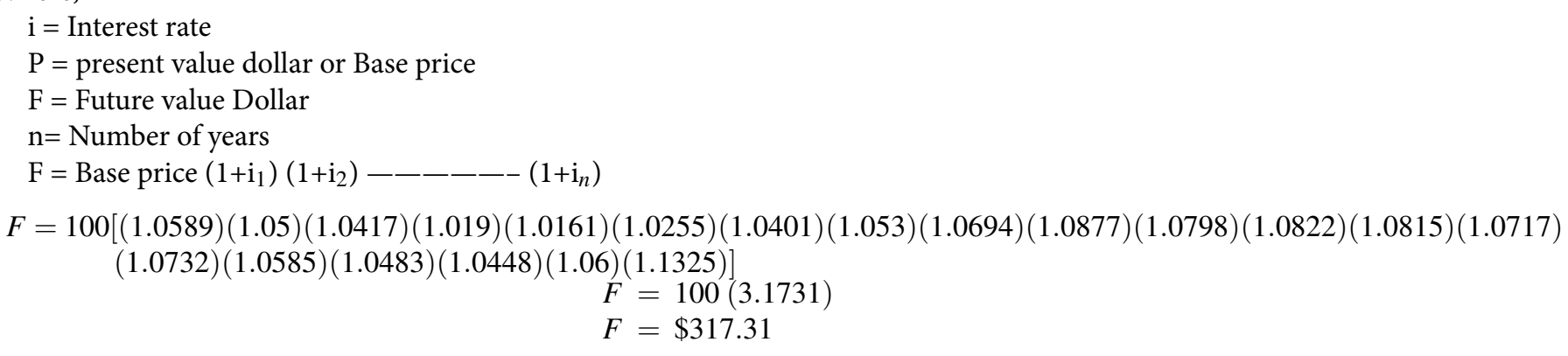

Now,

$$
\begin{aligned}
& \mathrm{i}=(\mathrm{F} / \mathrm{P})^{1 / \mathrm{n}}-1 \\
& \mathrm{i}=(317.31 / 100)^{1 / 20}-1 \\
& \mathrm{i}=1.0594-1
\end{aligned}
$$

Average interest rate of 20 years $=\mathrm{i}=0.0594$

\subsection{Inflation adjusted interest or Market Interest Rate for $\mathbf{2 0}$ years}

We know that

$$
\mathrm{i}_{\mathrm{f}}=\mathrm{i}+\mathrm{f}+(\mathrm{i} \times \mathrm{f})
$$

Substituting value of $i$ and $f$ in above equation we get,

$$
\begin{aligned}
& \mathrm{i}_{\mathrm{f}}=0.0594+0.0726+(0.0594 \times 0.0726) \\
& \mathrm{i}_{\mathrm{f}}=0.132+0.004312 \\
& \mathrm{i}_{\mathrm{f}}=0.1363 \\
& \mathrm{i}_{\mathrm{f}}=\mathbf{1 3 . 6 3} \%
\end{aligned}
$$




\section{Results and Discussion}

The cost analysis consists of initial investment cost, operation, and maintenance cost for a useful lifetime period of 20 years and expected salvage value after the useful life of the equipment. The cost of three selected DC Sources can be easily analyzed using cash flow diagrams mentioned in Figures 5, 6 and 7 below.

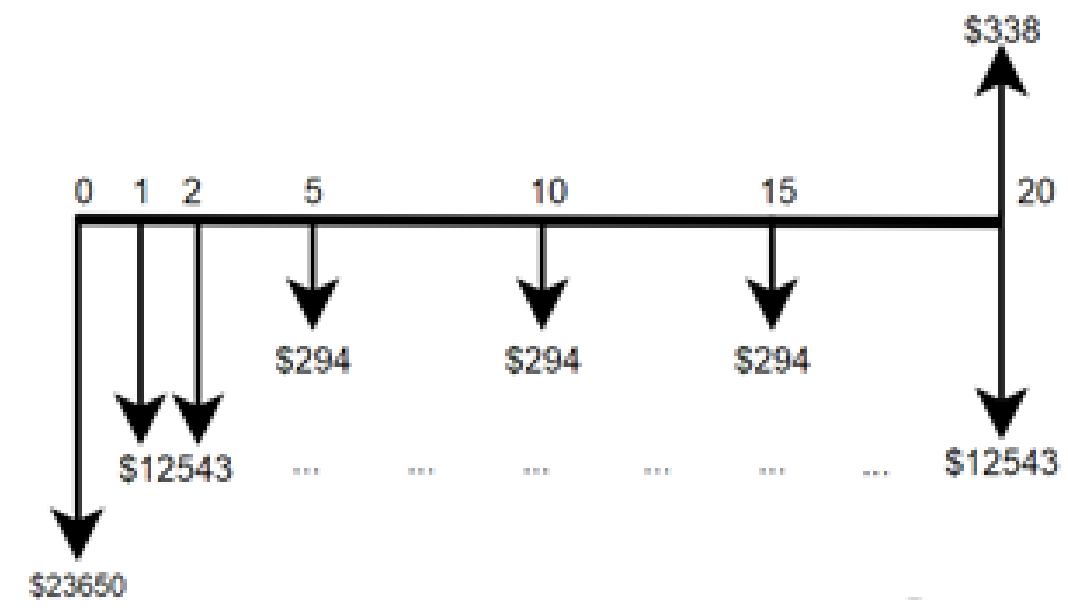

Fig 5. Cash flow diagram for Thermoelectric Generator

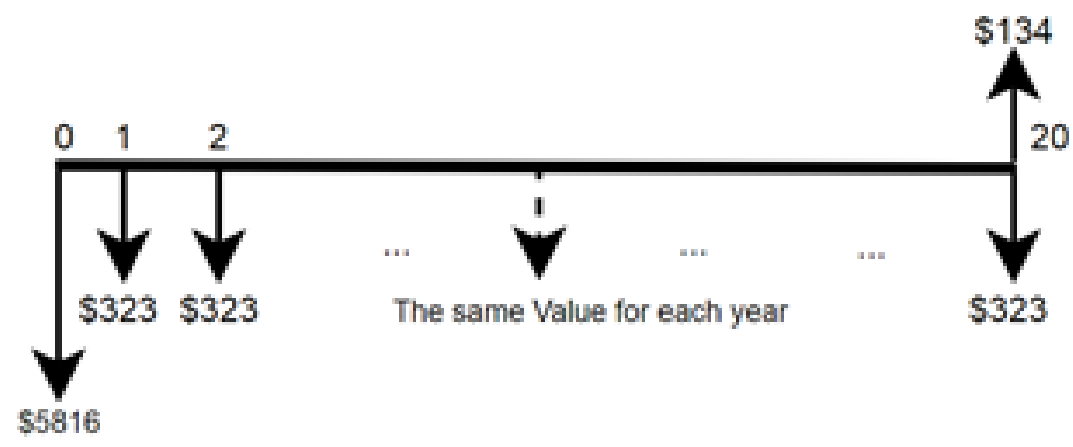

Fig 6. Cash flow diagram for Transformer Rectifier

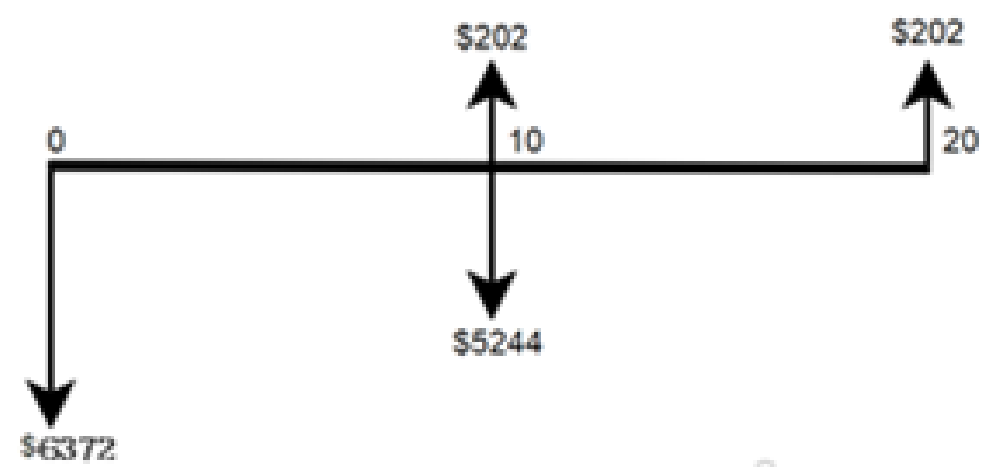

Fig 7. Cash flow diagram for Solar PV System 
The following spreadsheet formula is used for calculating the present worth of all the costs mentioned in cash flow diagrams for DC power source used in ICCP system. ${ }^{(7)}$

$$
=\mathrm{PV}(\mathrm{i} \%, \mathrm{n}, \mathrm{PMT}, F)
$$

PMT in above spreadsheet formula is the uniform annual maintenance cost. The results of spreadsheet calculations are given in Figures 8, 9 and 10

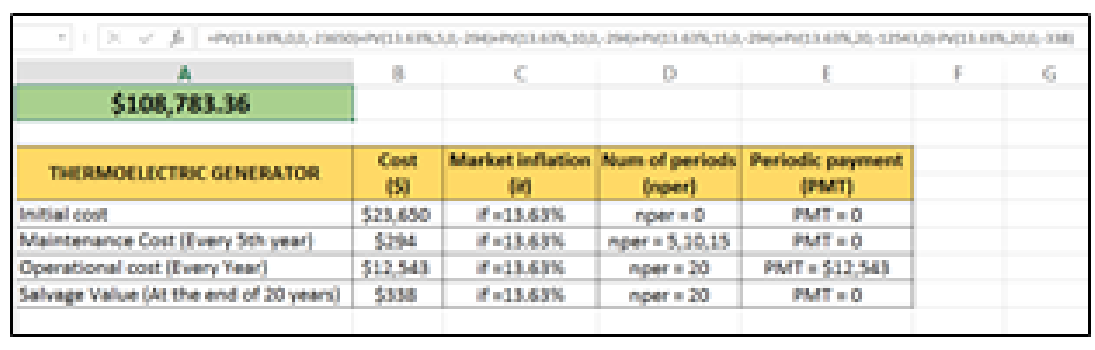

Fig 8. Spreadsheet Solution for Thermo Electric Generator

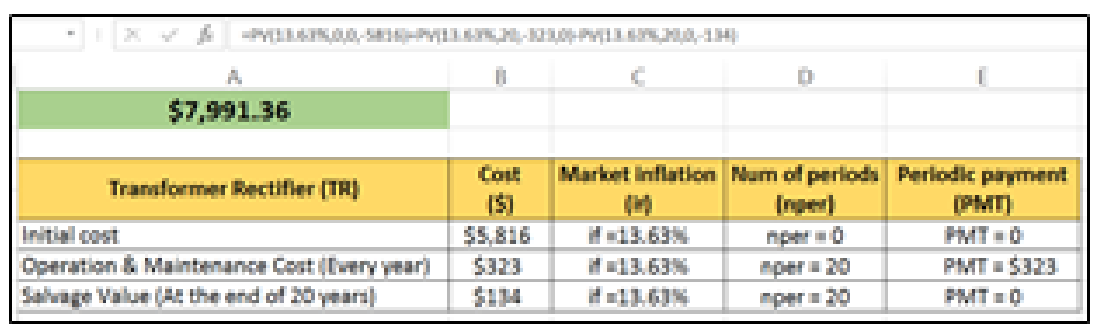

Fig 9. Spreadsheet Solution for Transformer Rectifier

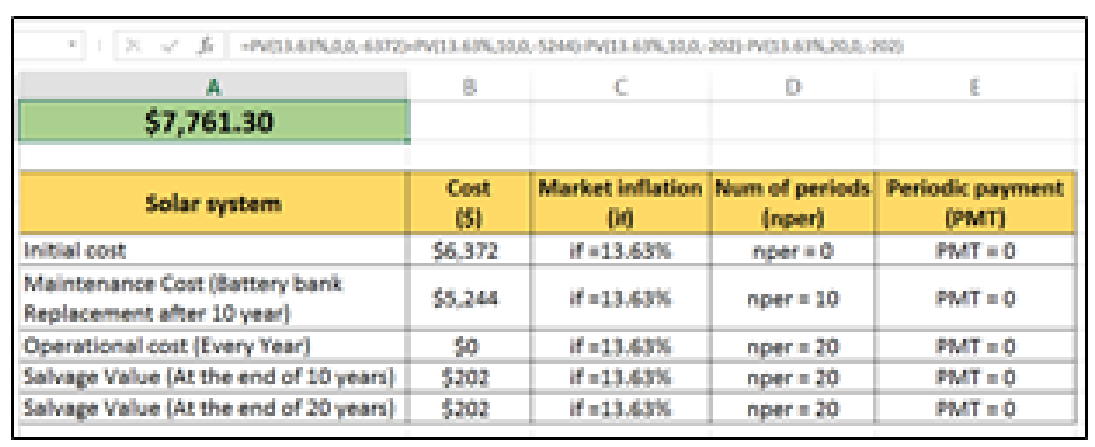

Fig 10. Spreadsheet Solution for PV Solar System

From the results of the spreadsheet calculation as mentioned in the above figures, it is evident that the solar PV system is the most economical system to be employed for Impressed Current Cathodic Protection system for protecting buried pipelines.

\section{Conclusion and Future Work}

Cathodic protection systems are used to protect buried and submerged metallic structures from corrosion. Impressed Current Cathodic Protection (ICCP) system is used for protecting larger metallic structures where the current requirement is high.

The focus of this research work is to mitigate the rate of corrosion in underground metallic pipelines in general and natural gas pipelines in particular, by integrating three different DC sources for a specified period at two different locations in the province of Balochistan. The selected locations are distinct from each other according to climate \& soil resistivity. 
The computed results also showed that the PV Solar system is an economical DC source for an ICCP system compared with that of the thermoelectric generator and Transformer rectifier. The calculation and measured results are quite straightforward based on real-time data. Further, unlike thermoelectric generator (TEG) and transformer rectifier (TR), the solar PV system is independent of commercial utility supply for its operation, which makes it more preferable, especially in areas with no commercial utility supply and enriched solar irradiations. Yet there exist some cons for all PV solar systems i.e. WeatherDependency. The proposed research will aid companies and industries in selecting the right type of external DC source while designing the ICCP system according to climate, versatility, output power intensity, and cost efficiency for corrosion protection of underground pipelines.

Further research is required in the field of corrosion control for buried pipelines. These underground pipelines play a vital role in the smooth and reliable transportation of chemical and petrochemical products. Corrosion in these pipelines can cause huge monetary and accidental losses. The rate of corrosion control in the high resistive environment can be possible through impressed current cathodic protection technique which uses a DC power source as a backbone element for its operation. Major research work had never been carried out in consideration of choosing an appropriate and efficient DC power source for an ICCP system concerning the type of electrolyte and the structure being protected. Therefore, the area of research is open for testing different types of DC sources especially renewable energy resources with the ICCP system for corrosion prevention of buried pipelines.

\section{References}

1) Adetunji OR, Obakhavbaye RA, Ajileye AK, Adesusi OM, Erinle TJ, Ipadeola SO, et al. Cathodic protection of underground mild steel pipes by impressed current using solar cells as rectifier. Journal of Innovative Solutions. 2019;2:12-22.

2) Khan MS, Kakar FK, Khan S, Athar SO. Efficiency and cost analysis of power sources in impressed current cathodic protection system for corrosion prevention in buried pipelines of Balochistan, Pakistan. IOP Conference Series: Materials Science and Engineering. 2018;414:1-10. doi:10.1088/1757899X/414/1/012034.

3) B SS, Pranav KP, R KR. Solar powered corrosion prevention in iron pipelines using Impressed Current Cathodic Protection. In: International Conference on Environment and Electrical Engineering (EEEIC). 2014;p. 372-377. doi:10.1109/EEEIC.2014.6835896.

4) Adly GS, Anis WR, Hafez IM. Design of photovoltaic powered Cathodic Protection System. International Journal of Scientific \& Technology. 2017;6(7):246253.

5) Byrne A, Norton B, Holmes N. State of the art review of cathodic protection for reinforced concrete structures. Magazine of Concrete Research. 2015;68(13):1-14. Available from: http://dx.doi.org/10.1680/jmacr.15.00083.

6) Guo W, Li X, Chen M, Xu L, Dong L, Cao X, et al. Electrochemical Cathodic Protection Powered by Triboelectric Nanogenerator. Advanced Functional Materials. 2014;24(42):6691-6699. Available from: https://doi.org/10.1002/adfm.201401168.

7) Park CS. Present Worth Analysis, Inflation, and its impact on project cash flows. In: Contemporary Engineering Economics. Pearson Education, Inc. 2007;p. 542-574.

8) Government of Pakistan. Pakistan Economic Survey (2014-15) and Finance Division. 2015. 